\title{
A Multi-Layer Based Assessment of Wetland Changes in the Southern Iraqi Marshlands Using Remotely Sensed Data
}

\author{
Felix Ike $^{1 *}$, Chinyere Ruth Ottah ${ }^{1,2}$ \\ ${ }^{1}$ Department of Geography and Planning, Abia State University, Uturu, Nigeria \\ ${ }^{2}$ Department of Geography, University of Portsmouth, Portsmouth, UK \\ Email: *chiemzy@yahoo.com
}

How to cite this paper: Ike, F. and Ottah, C.R. (2019) A Multi-Layer Based Assessment of Wetland Changes in the Southern Iraqi Marshlands Using Remotely Sensed Data. International Journal of Geosciences, 10, 801-810.

https://doi.org/10.4236/ijg.2019.109045

Received: August 7, 2019

Accepted: September 16, 2019

Published: September 19, 2019

Copyright $\odot 2019$ by author(s) and Scientific Research Publishing Inc. This work is licensed under the Creative Commons Attribution International License (CC BY 4.0).

http://creativecommons.org/licenses/by/4.0/

\begin{abstract}
Marshlands are important ecosystem for living organisms. The Southern Iraqi Marshland is the central habitat for freshwater fish, provides habitat for important populations of wildlife and serves as a source of income for native economies through reed harvesting. Studies have shown that variability in climate and human-induced factors affects the spatial dynamics of marsh ecosystems. This study assessed wetland changes in the Southern Iraqi Marshlands using Remotely Sensed Data from 1986 to 2019 using Landsat satellite imagery for four epochs: 1986, 2000, 2010 and 2019. To achieve this, thirty (30) pixels were obtained in selected land cover theme and their signatures were merged into one class. Furthermore, the selected pixels were re-coded and merged into ten (10) land cover classes. The multi-layer classes created were shallow water, deep water, dense marsh, medium marsh, sparse marsh, dense vegetation, medium vegetation, sparse vegetation, dry soil and wet soil. The areal extents of the land cover types were calculated for 1986, 2000, 2010 and 2019. Normalized Difference Vegetation Index (NDVI) differencing was also carried in order to highlight trends in vegetation from 1986 to 2019. The study correlated historical trends of human activities as a central factor in the degradation of marshland (by 16.25\%) from 1986 to 2000. However, by the year 2000 to 2010, there was an $11.36 \%$ increase in the total marshland area, which remained almost unchanged between 2010 and 2019. In 1986, NDVI was relatively stable at 0.73 in the Al-Hammar and Al-Hwaizeh Marsh. However, by 2000 , the areas of dense vegetation cover reduced drastically by over $90 \%$. In 2010, the NDVI index indicated trends of increasing water body and an outward cluster of healthier vegetation continuing to 2019 .
\end{abstract}

\section{Keywords}

Marshland NDVI, Pixel Reed Harvesting 


\section{Introduction}

Marshlands of the world are seen as an important ecosystem for living organisms and the environment, serving as a source of income for native economies through reed harvesting and fishing [1]. The Iraqi Marshland is considered to be one of the most important marshlands in the world: the largest ecosystem in Eastern and Western Asia. It is the eleventh non-marine marshland with Endemic Bird area status [2] and central habitat for Gulf's freshwater fish [3].

The marsh land is home to 500,000 native Marsh Arabs [1]; and of the world's oldest western civilization point. In 1985, levees were built and part of the marshes was drained by the Iraq government to develop oil fields discovered within the marshlands [4].

The Iraqi marshlands-originally twice the size of the Everglades in Florida-has been the major wetland area in the Middle East, as of 1990, very little had changed in the region. However, within a decade, 90 percent of the ecosystem area was turned into barren dry lands by a large drainage scheme. Additional important roles provided by marshes include detention of floodwaters, protection of shorelines from erosion, aesthetics, and improvement of water quality by trapping sediments and assimilating nutrients.

In recent times, remotely sensed imageries have been used to monitor and map wetlands changes on a global scale [5]; especially in areas with inadequate ground-based observations [6]. Due to the vast size and remoteness of the Iraqi marshlands, remote sensing is needed to monitor the dynamics and levels of change of its sensitive ecosystem.

\section{Data and Methodology}

\subsection{Study Area}

The southern Mesopotamian marshes lie in the southern part of Iraq, cutting across three of Iraqi's Provinces. It is along latitudes $29^{\circ} 55^{\prime}$ to $32^{\circ} 55^{\prime} \mathrm{N}$ and longitudes $45^{\circ} 25^{\prime}$ to $48^{\circ} 30^{\prime} \mathrm{E}$ (See Figure 1). The marsh land is made up of three structures, namely, the $\mathrm{Al} \mathrm{Hammar}$, Central Marshes and Al-Hawizeh. The Al-Hammar Marsh is located towards the south of the Euphrates River and extends from Al-Nasiriyah to Al-Basra in the east. The Central marshes are located amid the Euphrates and the Tigris Rivers. Al-Hawizeh Marsh is situated towards the south of Al-Basara and northern part of Al-Amarah. The Iranian section of the marshes is referred to as the Hawr Al-Azim [4].

\subsection{Data Analysis}

Landsat imageries from https://earthexplorer.usgs.gov were acquired for four epochs (1986, 2000, 2010 and 2019), layer stacked and mosaic. Radiometric and geometric errors were reduced by colour correction and feathering respectively. The Landsat imageries were first corrected for geometric (through georeferencing), and radiometric (through filtering) errors to correct for locational misplacement based on [7]. All the data sets were collected between January and May each year (Table 1). 
Table 1. Characteristics of the used Landsat images.

\begin{tabular}{ccc}
\hline Data type & Acquisition Date & Resolution in meters (M) \\
\hline Landsat 5 TM & $6 / 5 / 1986$ & $30 \times 30 \mathrm{M}$ \\
Landsat 5 TM & $31 / 5 / 1986$ & $30 \times 30 \mathrm{M}$ \\
Landsat 7 ETM+ & $4 / 5 / 2000$ & $30 \times 30 \mathrm{M}$ \\
Landsat 7 ETM+ & $13 / 5 / 2000$ & $30 \times 30 \mathrm{M}$ \\
Landsat 5 TM Path 166038 & $22 / 5 / 2010$ & $30 \times 30 \mathrm{M}$ \\
Landsat 5 TM Path 166039 & $7 / 5 / 2010$ & $30 \times 30 \mathrm{M}$ \\
Landsat 5 TM Path 167038 & $16 / 1 / 2010$ & $30 \times 30 \mathrm{M}$ \\
Landsat 5 TM Path 167039 & $1 / / 2010$ & $30 \times 30 \mathrm{M}$ \\
Landsat 8 Path 166038 & $26 / 5 / 2019$ & $30 \times 30 \mathrm{M}$ \\
Landsat 8 Path 166039 & $26 / 5 / 2019$ & $30 \times 30 \mathrm{M}$ \\
Landsat 8 Path 167038 & $10 / 5 / 2019$ & $30 \times 30 \mathrm{M}$ \\
Landsat 8 Path 167038 & $25 / 5 / 2019$ & $30 \times 30 \mathrm{M}$ \\
\hline
\end{tabular}

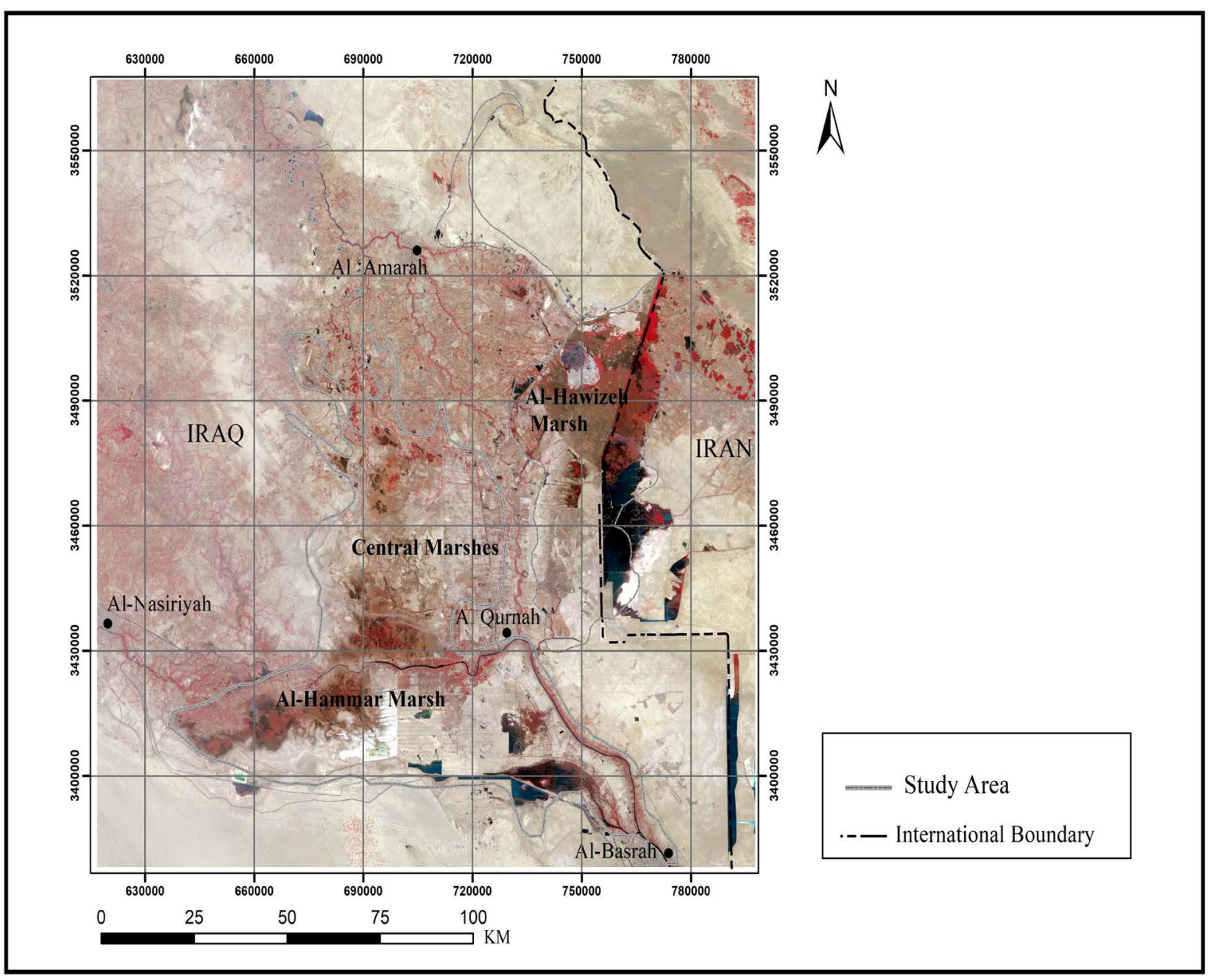

Figure 1. The study area. 
The supervised classification technique using Maximum Likelihood Algorithm (MLC) was used. This allowed for a multivariate normal distribution to be used to represent an individual spectral class [8]. Training data were collected using the polygon method. Thirty (30) pixels were obtained in each land cover theme and the selected signatures of the same pixel were merged into one class. The 30 multi-layer classes were re-coded and merged into ten (10) land cover classes. The classes created are shallow water, deep water, dense marsh, medium marsh, sparse marsh, dense vegetation, medium vegetation, sparse vegetation, dry soil and wet soil. These classes were selected from the Landsat ETM classification scheme of the Iraqi Marshlands Observation System (available at: https://postconflict.unep.ch/publications/UNEP_IMOS.pdf). The Normalized Difference Vegetation Index (NDVI) analysis was also carried in order to highlight trends in vegetation from 1986 to 2019.

ERDAS Imagine 2018 was used to carry out the supervised classification, whilst ArcGIS 10.6 was used to include map marginalia. The level of accuracy of the classification of the land cover change of the imageries showed the 1986 imagery was less accurate than others, given the $77 \%$ overall accuracy (Kappa coefficient $=0.72$ ). Respectively, there was an $86 \%$ overall accuracy (Kappa coefficient $=$ 0.82 ), $86 \%$ overall accuracy (Kappa coefficient $=0.82$ ) and $92 \%$ overall accuracy (Kappa coefficient $=0.9$ ) for 2000, 2010 and 2019 imageries.

\section{Results}

The land covers distribution and changes that took place on the marshland are shown in Table 2.

Table 2. Land cover of South Iraqi Marshlands.

\begin{tabular}{|c|c|c|c|c|c|c|c|c|}
\hline \multirow{2}{*}{$\begin{array}{c}\text { Land Cover } \\
\text { Category }\end{array}$} & \multicolumn{2}{|c|}{1986} & \multicolumn{2}{|c|}{2000} & \multicolumn{2}{|c|}{2010} & \multicolumn{2}{|c|}{2019} \\
\hline & $\begin{array}{l}\text { Area } \\
\left(\mathrm{km}^{2}\right)\end{array}$ & $\begin{array}{l}\text { Area } \\
(\%)\end{array}$ & $\begin{array}{l}\text { Area } \\
\left(\mathrm{km}^{2}\right)\end{array}$ & $\begin{array}{c}\text { Area } \\
(\%)\end{array}$ & $\begin{array}{l}\text { Area } \\
\left(\mathrm{km}^{2}\right)\end{array}$ & $\begin{array}{c}\text { Area } \\
(\%)\end{array}$ & $\begin{array}{l}\text { Area } \\
\left(\mathrm{km}^{2}\right)\end{array}$ & $\begin{array}{c}\text { Area } \\
(\%)\end{array}$ \\
\hline Shallow Water & 849.83 & 2.49 & 398.65 & 1.17 & 258.34 & 0.76 & 527.53 & 1.54 \\
\hline Deep Water & 666.87 & 1.95 & 402.5 & 1.18 & 535.99 & 1.57 & 644.17 & 1.89 \\
\hline Dense Marsh & 1716.55 & 5.02 & 215.97 & 0.63 & 736.02 & 2.15 & 11.93 & 0.03 \\
\hline Medium Marsh & 4258.39 & 12.47 & 992.11 & 2.90 & 3593.61 & 10.52 & 3286.35 & 9.62 \\
\hline Sparse Marsh & 1033.95 & 3.03 & 250.41 & 0.73 & 1009.2 & 2.95 & 1357.73 & 3.98 \\
\hline Dense Vegetation & 372.53 & 1.09 & 98.09 & 0.29 & 5.13 & 0.015 & 1.25 & 0.00 \\
\hline $\begin{array}{c}\text { Medium } \\
\text { Vegetation }\end{array}$ & 5522.88 & 16.17 & 656.92 & 1.92 & 293.33 & 0.86 & 120.22 & 0.35 \\
\hline Sparse Vegetation & 9374.7 & 27.44 & $13,059.67$ & 38.23 & $11,094.5$ & 32.48 & 7704.85 & 22.55 \\
\hline Dry Soil & $10,291.3$ & 30.12 & $17,925.39$ & 52.47 & $16,439.1$ & 48.12 & $19,758.3$ & 57.84 \\
\hline Wet Soil & 75.12 & 0.22 & 162.42 & 0.48 & 196.9 & 0.58 & 749.79 & 2.19 \\
\hline Total & $34,162.12$ & $100 \%$ & $34,162.12$ & $100 \%$ & $34,162.12$ & $100 \%$ & $34,162.12$ & $100 \%$ \\
\hline
\end{tabular}


From Table 2 and as illustrated in Figure 2, the total area of marshland in 1986 was $7008.89 \mathrm{~km}^{2}$ (Dense Marsh $1716.55 \mathrm{~km}^{2}$, Mdedium Marsh $4258.39 \mathrm{~km}^{2}$ and Sparse Marsh $\left.1033.95 \mathrm{~km}^{2}\right)$.

Vegetation occupied a total area of $15,270.1 \mathrm{~km}^{2}(44.69 \%)$ and was dominated by sparse vegetation $(27.44 \%)$.

By the year 2000 (Figure 3), medium marshland areas reduced by about $9.56 \%$ (Table 3) for a decreased total marshland area of $1458.49 \mathrm{~km}^{2}$ (Dense + Medium + Sparse) Shallow and deep-water bodies reduced by $1.3 \%$ and $0.77 \%$ from 1986 to 2000 .

Table 3. Annual trend change.

\begin{tabular}{cccc}
\hline Land Cover & $1986-2000$ & $2000-2010$ & $2010-2019$ \\
\hline Shallow Water & -1.32 & -0.41 & +0.79 \\
Deep Water & -0.77 & +0.39 & +0.32 \\
Dense Marsh & -4.39 & +1.52 & -2.12 \\
Medium Marsh & -9.56 & +7.62 & -0.90 \\
Sparse Marsh & -2.29 & +2.22 & +1.02 \\
\hline Dense Vegetation & -0.80 & -0.27 & -0.01 \\
Medium Vegetation & -14.24 & -1.06 & -0.51 \\
Sparse Vegetation & +10.79 & -5.75 & -9.92 \\
Dry Soil & +22.35 & -4.35 & +9.72 \\
\hline Wet Soil & +0.26 & +0.10 & +1.62 \\
\hline
\end{tabular}

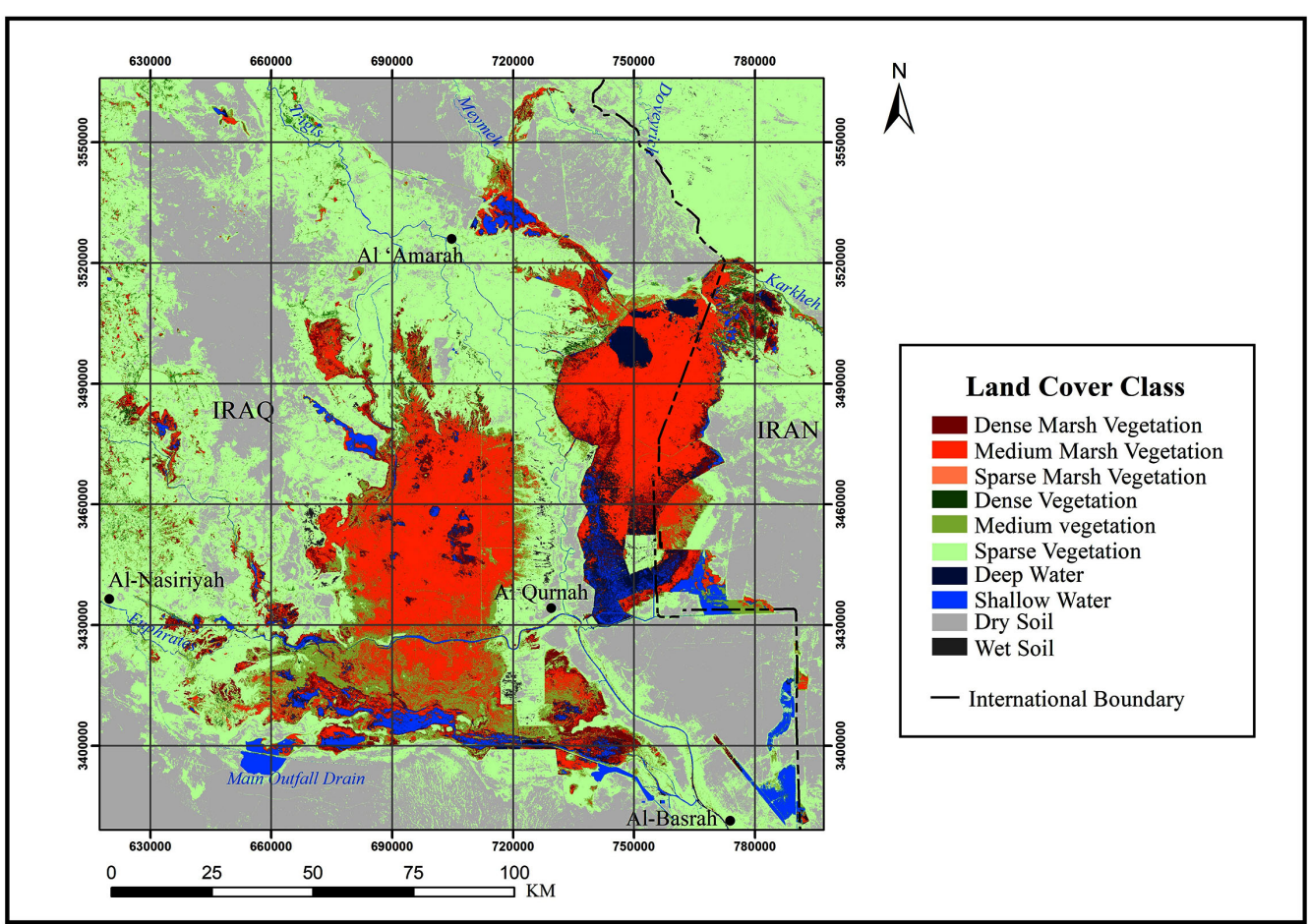

Figure 2. Land cover class of the Southern Iraqi Marshland in 1986. 


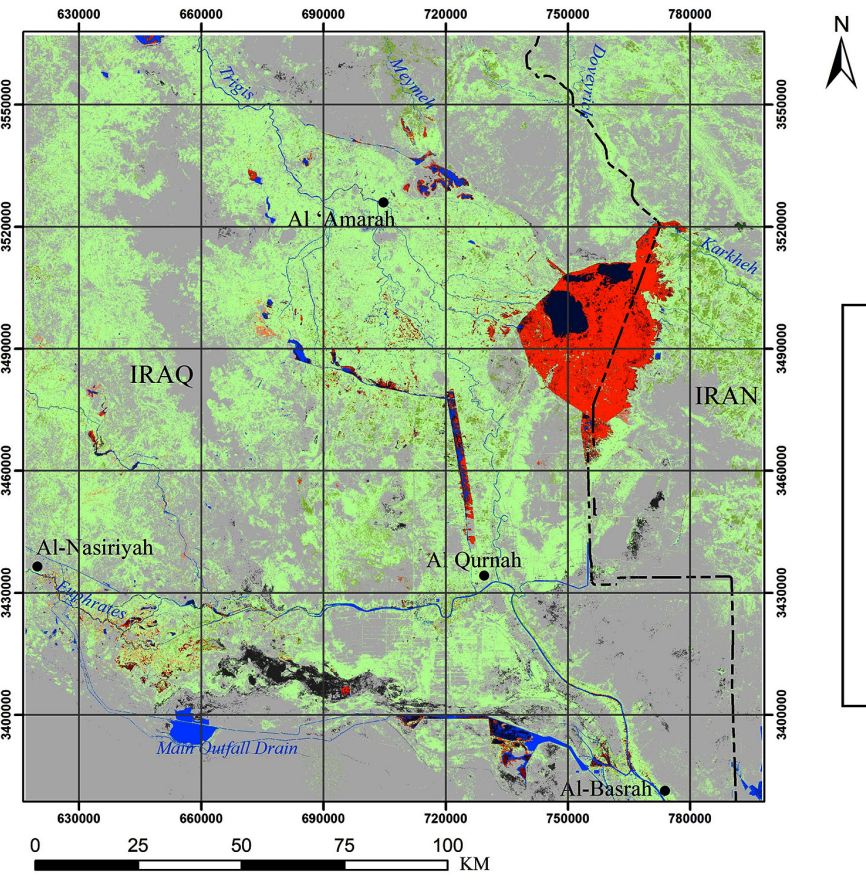

$\stackrel{N}{N}$

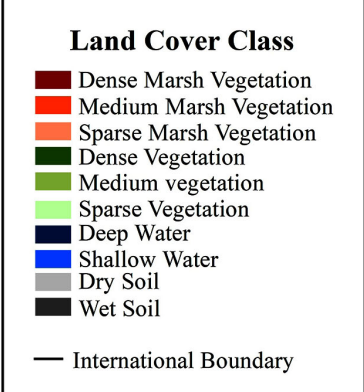

Figure 3. Land cover class of the Southern Iraqi Marshland in 2000.

Hence, most of the marshes degraded to sparse vegetation and increased dry soil area. This disappearance can be attributed to anthropogenic activities [9], as well as unforeseen conditions, including droughts and high temperatures [10].

In the year 2010 (Figure 4), there was a 1.52\% increase in dense marshland for a total increased marshland area of $5338.83 \mathrm{~km}^{2}$ (Dense + Medium + Sparse). This corresponds to about $11.35 \%$ increase in the total marshland area from the year 2000 to 2010 .

Whilst shallow water bodies increased (notably in the northeast of Al-Basra), deep waters reduced by about the same margin.

The increase in the marshland areas and that of the shallow water areas can be attributed to the ensuing anthropogenic activities at the end of the Second Gulf War and of Saddam Hussein's regime in the year 2003. The dykes and canals that once drained the marshes were destroyed, thus re-flooding several large marsh areas of the Euphrates [11]. More so, towards the end of the year 2005, a two (2) year snowpack melts in Turkey and Iran resulted in a large volume of incoming water from the Tigris and Euphrates Rivers to the marshes [2] hence the total dry soil area decreased by $4.37 \%$ in 2010 .

From the year 2010 to 2019 (Figure 5), there was only but a little progress in the marshland recovery. With a total area of $5338.83 \mathrm{~km}^{2}$ (Dense + Medium + Sparse) occupied by marshland, this shows only about $1.99 \%$ increase from the year 2010 .

\section{Trends in NDVI}

In the year $1986 \mathrm{NDVI}$ was relatively stable at 0.73 in the Al-Hammar marsh. 


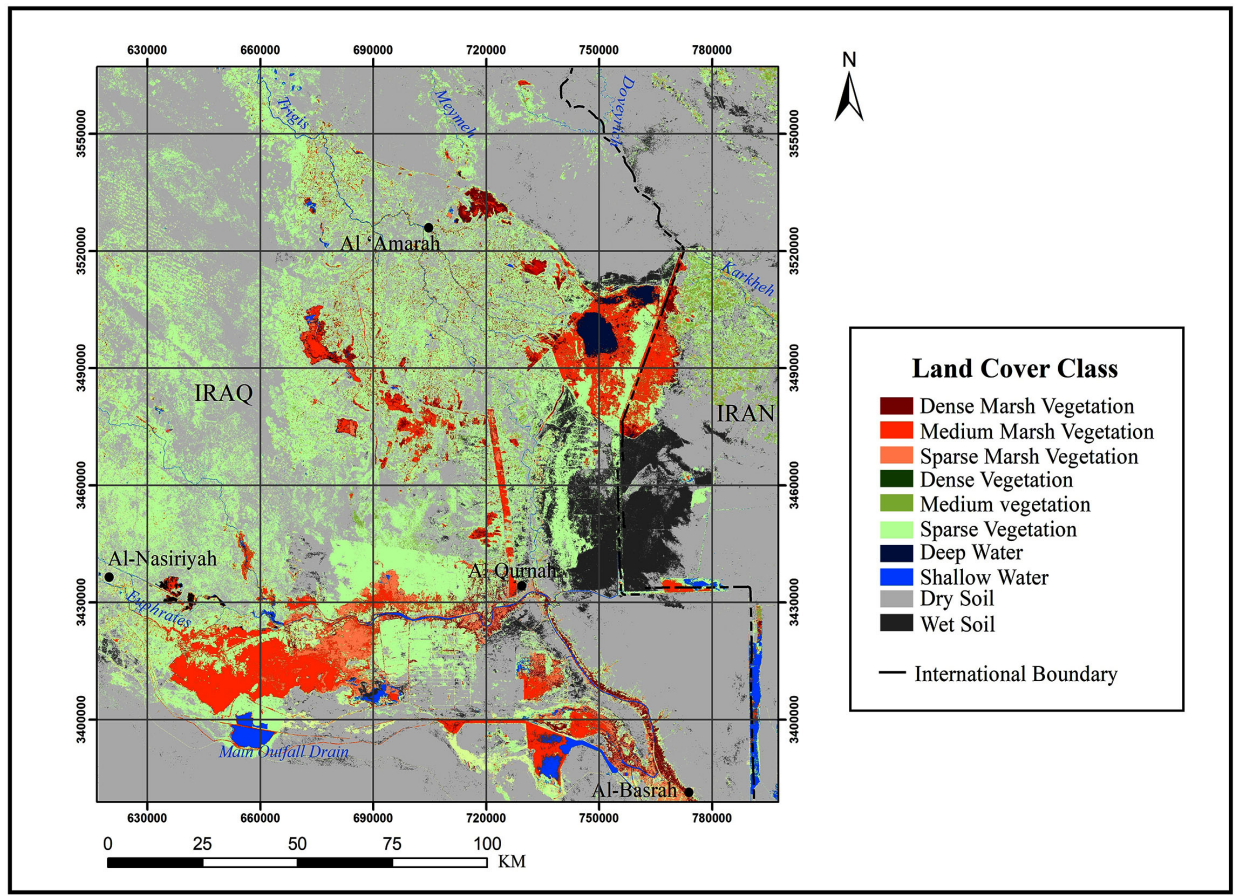

Figure 4. Land cover class of the Southern Iraqi Marshland in 2010.

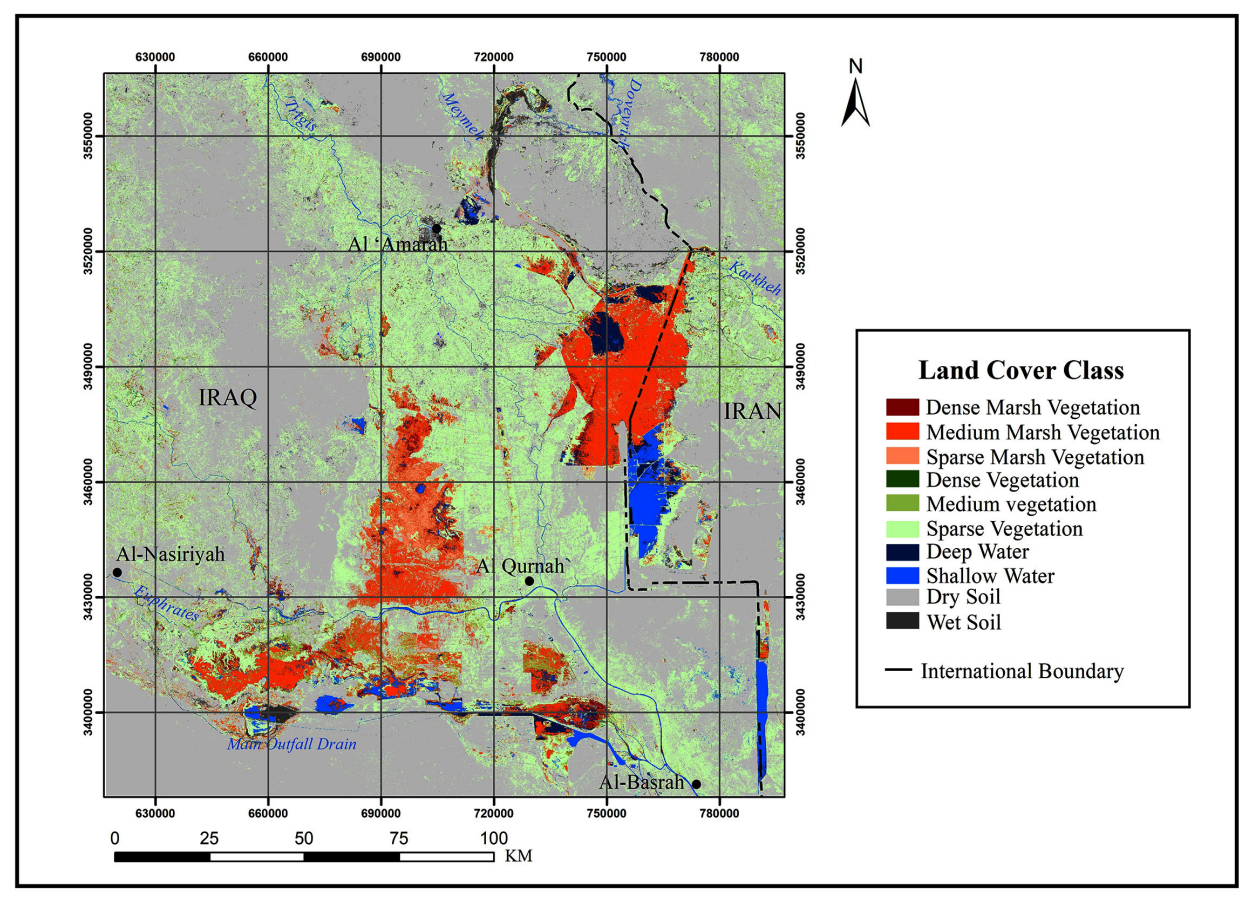

Figure 5. Land cover class of the Southern Iraqi Marshland in 2019.

Central marsh and the Al-Hwaizeh Marsh is indicative of a relatively large vegetative cover area. In contrast, the areas of dense vegetation cover reduced drastically by the year 2000 (Figure 6). During this period, the north of Al-Hwaizeh Marsh, the Al-Hammar and Central marshlands with formerly healthy dense vegetation; degenerated to unhealthy shrubs. 
By the year 2010, the NDVI index varied from -1 to 1 ; indicative of increasing water body areas and an outward cluster growth of healthier vegetation (AlHammar, central and Al-Hwaizeh marsh areas).

This is evidenced in the 2000 to 2010 NDVI change detection in Figure 7 and extends into the 2010 to 2019 NDVI change detection in Figure 8. This vegetative cover improvement is a result of the collective effort by Iraq's government and international agencies to support the restoration of the marshes [12].

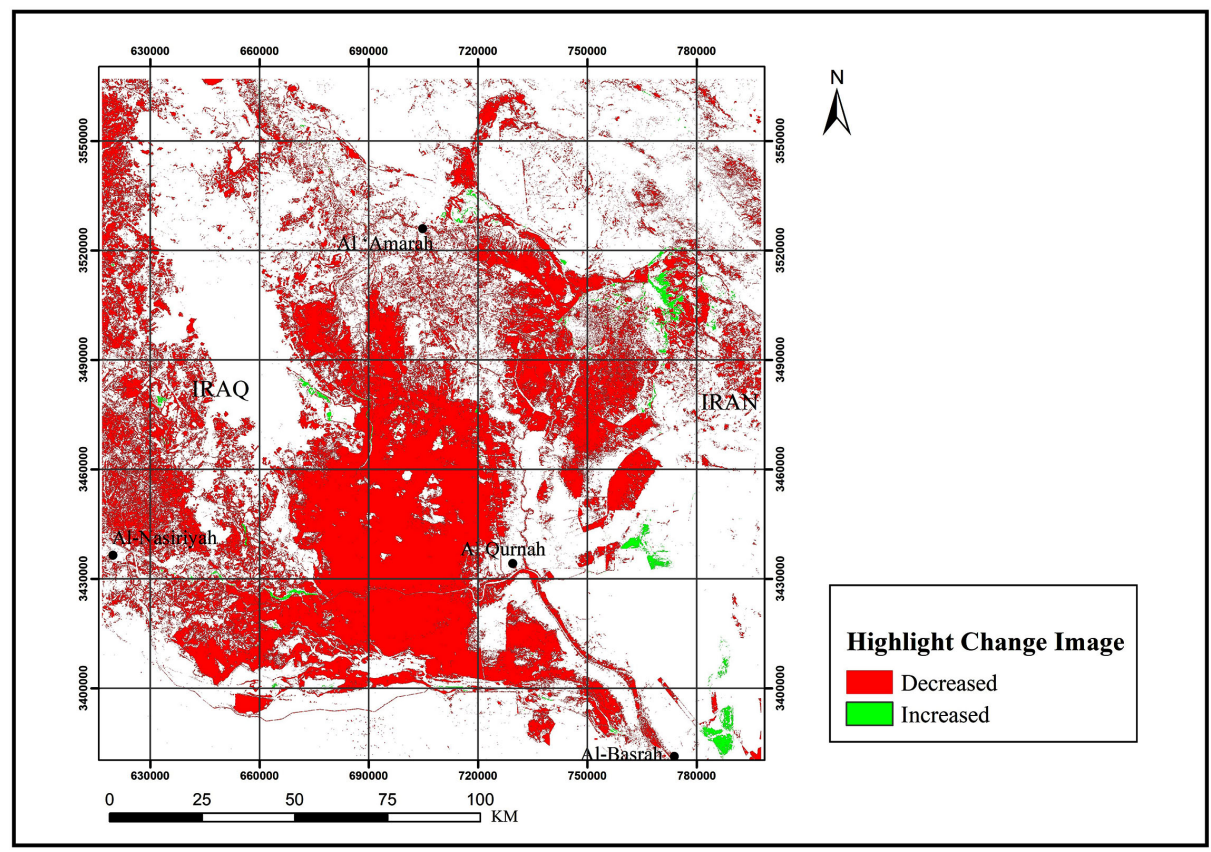

Figure 6. Spatial trends in NDVI between 1986 and 2000.

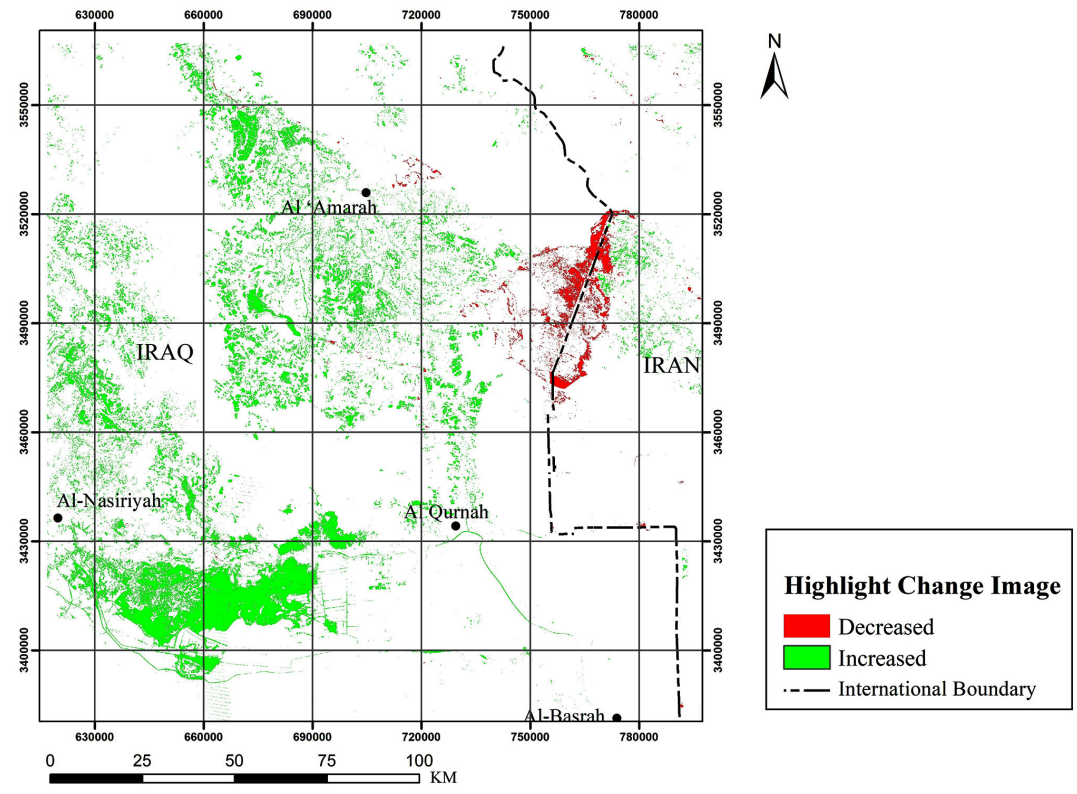

Figure 7. Spatial trends in NDVI between 2000 and 2010. 


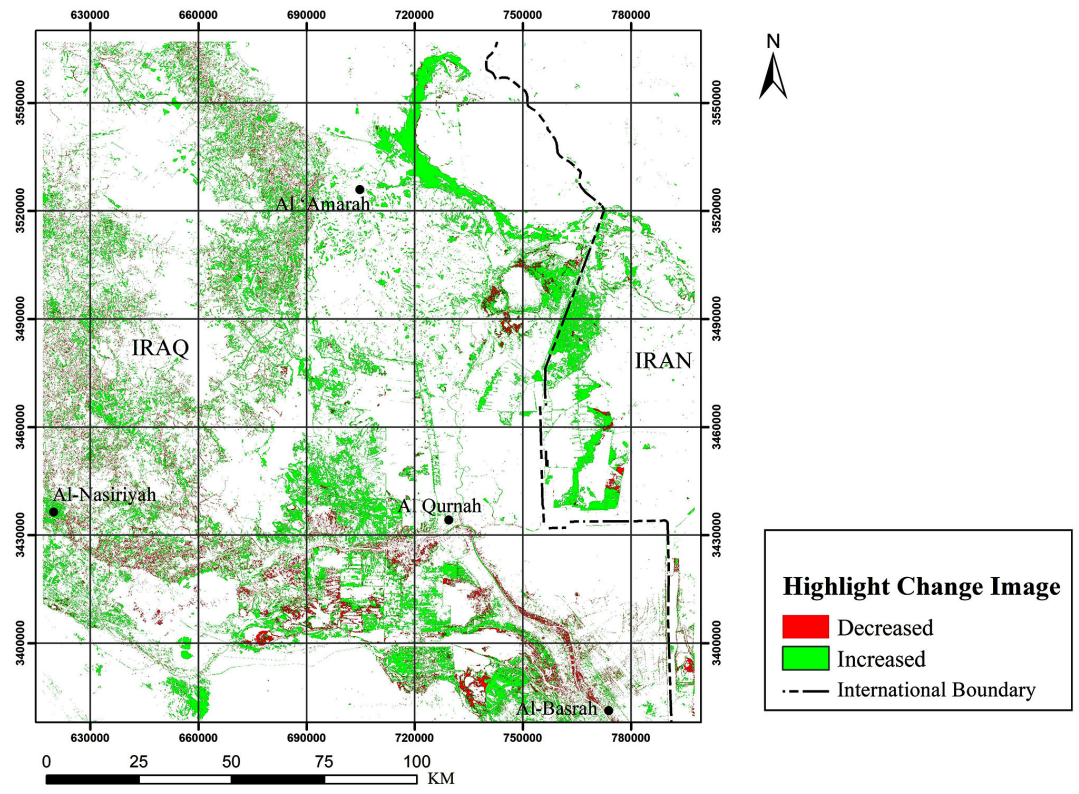

Figure 8. Spatial trends in NDVI between 2000 and 2010.

\section{Conclusion}

This study has demonstrated the applicability of remote sensing technique in monitoring changes on sensitive ecosystems. It also highlights how historical footprints of human activities affected the land cover and NDVI trends in the study area. This study, therefore, suggests that efforts to restore the southern marshlands of Iraq should be sustained and further studies are required to ascertain the levels of variability in climate and its effect on the dynamics of the Iraq marshes.

\section{Conflicts of Interest}

The authors declare no conflicts of interest regarding the publication of this paper.

\section{References}

[1] Albarakat, R., Lakshmi, V. and Tucker, C.J. (2018) Using Satellite Remote Sensing to Study the Impact of Climate and Anthropogenic Changes in the Mesopotamian Marshlands, Iraq. Remote Sensing, 10, 1524. https://doi.org/10.3390/rs10101524

[2] Richardson, C.J. and Hussain, N.A. (2006) Restoring the Garden of Eden: An Ecological Assessment of the Marshes of Iraq. BioScience, 56, 477-489. https://doi.org/10.1641/0006-3568(2006)56[477:RTGOEA]2.0.CO;2

[3] Scott, D.A. (1995) A Directory of Wetlands in the Middle East. IUCN, Gland, Switzerland.

[4] Hussain, E. and Aluauee, N. (2018) Analysis of Environmental Changes in Iraq Marshes by Remote Sensing.

[5] Rogan, J., Franklin, J. and Roberts, D.A. (2002) A Comparison of Methods for Monitoring Multitemporal Vegetation Change Using Thematic Mapper Imagery. Remote Sensing of Environment, 80, 143-156. 
https://doi.org/10.1016/S0034-4257(01)00296-6

[6] Ozesmi, S.L. and Bauer, M.E. (2002) Satellite Remote Sensing of Wetlands. Wetlands Ecology and Management, 10, 381-402.

https://doi.org/10.1023/A:1020908432489

[7] Das, S., Patel, P.P. and Sengupta, S. (2016) Evaluation of Different Digital Elevation Models for Analyzing Drainage Morphometric Parameters in a Mountainous Terrain: A Case Study of the Supin-Upper Tons Basin, Indian Himalayas. SpringerPlus, 5, 1544. https://doi.org/10.1186/s40064-016-3207-0

[8] Xiong, L. (2005) Supervised Classification and Unsupervised Classification. ATS 670 Class Project, 1-12.

[9] UNEP (2001) Early Warning and Assessment Report: The Mesopotamian Demise of an Ecosystem. The Mesopotamian Marshlands: Environment.

[10] Nadia, A. and Malik, A.H. (2012) Restoring the Marshlands of Iraq. In: Keenleyside, K.A., Dudley, N., Cairns, S., Hall, C.M. and Stolton, S., Eds., Ecological Restoration for Protected Areas. Principles, Guidelines and Best Practice, IUCN, Gland, Switzerland, 93-95.

[11] National Aeronautics and Space Administration (NASA) (2010) World of Change: Mesopotamia Marshes. https://earthobservatory.nasa.gov/world-of-change/Iraq

[12] Garstecki, T. and Amr, Z. (2011) Biodiversity and Ecosystem Management in the Iraqi Marshlands Screening Study on Potential World Heritage Nomination. 